\title{
Eco-Controlling: Prospects for the Environmental Policy in Enterprise Management
}

\author{
Hanna Matukova ${ }^{1}$, Valentyna Khrapkina ${ }^{2}$, Natalia Bahashova ${ }^{3 *}$, Daria Matukova-Yaryha ${ }^{1}$ and Alla Levitskaia ${ }^{4}$ \\ ${ }^{1}$ National Medical University named after O.O. Bohomolets, 01601 Kyiv, Ukraine \\ ${ }^{2}$ National University of Kyiv-Mohyla Academy, 04655 Kyiv, Ukraine \\ ${ }^{3}$ State University Economics of Technology, 50005 Kryvyi Rih, Ukraine \\ ${ }^{4}$ Comrat State University, «Innotsentr», MD-3801 Republic of Moldova Comrat
}

\begin{abstract}
The research defines eco-controlling as a new trend of the enterprise environmental policy in the field of environmental protection, its place in the enterprise control system under conditions of permanent changes of the economic environment and environmental challenges. There are outlined tasks of eco-controlling that covers a wide variety of issues associated with ensuring the enterprise's effective activity in the long run considering requirements of environmental protection. The authors substantiate efficiency of introducing eco-controlling as a set of tasks of planning, accounting, controlling, analyzing and auditing environmental aspects of industrial enterprises' activity.
\end{abstract}

\section{Introduction}

To avoid consequences of irresponsible, irrational or consciously criminal use of natural resources in various life activity spheres both locally and globally, it is reasonable to concentrate on search, identification, theoretical substantiation and practical introduction of managerial technologies of efficient natural resources use. It is required to consider opportunities, trends, ways and aims of using any natural resources and make thoroughly grounded, economically feasible and materially secure results. In other words, without implementing smart resource management, we will not be able to form economically efficient methods of social natural-production to achieve sustainability by activating cognitive processes [1].

Nowadays, smart management is the foundation of environmental culture that implies understanding, formation and support of such economic relations the evaluative prerogative of which is sustainable attitude of economic entities to the environment with simultaneous obtainment of stable economic advantages. Being aimed at sustainable development, culture of intellectually substantiated production of goods and services required for society will imply either complete refusal to manufacture necessary, yet environmentally unfriendly products (unrenewable elimination of natural resources, contamination of the environment with industrial and household wastes) or application of people's intellectual potential to avoid the need to eliminate or to exhaust natural resources in order to receive economic wealth the total value of which determines the economic boost level, yet fails to restore the resources lost.

Thus, global use of natural resources demands arrangement of global smart management. This arouses a

*Corresponding author: bahashova nv@kneu.dp.ua specific interest in the concept of rationalism in natural resource use in which culture of global natural resource use is considered in the context of human socially, environmentally and economically intellectualized activity. Nowadays, illegal waste dumps are made spontaneously without any engineering and environmental assessment of the negative impact level for adjacent territories. During illegal waste storage, the measures for reducing the technogenic load are neglected, there is no control of the morphological composition of wastes transported, this not excluding possible storage of medical, toxic or other hazardous waste types coming. Organic wastes within solid household wastes cause creation of sources of rodent and insect reproduction, which can worsen the epidemiological situation. Solid household wastes decompose at waste dumps due to special combination of chemical, physical and biological processes. This results in solid, liquid and gaseous secondary substances and materials. Thus, organic acids, phenol, aldehydes, ammonia, nitrites, etc. are decomposition products of paper and food wastes. Carbon dioxide, methane, hydrogen sulphide, volatile organic acids are gaseous decomposition products [2].

Decomposition periods for different household wastes are the following:

- paper - from a few months to a few years depending on its quality; it decomposes to organic compounds; chalk overlay and coloured paper decompose longer; decomposition of chalk overlay and coloured paper takes longer: 
- glass - several thousands of years, it decomposes to the state of sand;

- cans - from 10 to 30 years depending on quality; the cover of iron cans slows down their decomposition; they decompose to iron compounds;

- plastic bottles - about 400 years (they contain urethane, phenol, formaldehyde, styrol);

- leather footwear - from 25 to 40 years;

- batteries - 110 years, they contain heavy metals (zinc, manganese, copper, cadmium, mercury [3].

The authors suggest conducting rapid analysis of the enterprise's state by calculating and then analyzing the following coefficients:

1) financial stability (autonomy, times interest earned (TIE), net working capital, mobility);

2) liquidity (current/fast/absolute liquidity);

$3)$ profitability/return (return on equity (ROE), return on sales (ROS));

4) dynamics of development (dynamics of sales, dynamics of assets, dynamics of net income);

5) turnover (days sales in inventory, time of debit debt turnover, time of credit debt turnover), and

6) conduction of eco-controlling.

The suggested list of indices for analysis can be disputable as to its completeness, yet it should be mentioned that it meets the requirements of clearness and simplicity of assessing the financial state and dynamics of an entity's development and is the most applicable to practice [3, 4].

\section{Results}

Environmental audit as a mechanism for environmental management was developed in the economically developed countries of the USA, Canada, Great Britain, Germany, etc. - in the 70s. Environmental audit began to develop as a branch of entrepreneurial activity in the environmental industry [5].

An innovation in the domestic legal system was the introduction of the so-called mandatory environmental audit (along with the traditional form of voluntary environmental audit). which should be exposed to objects that pose an increased environmental hazard, by order of the concerned executive authorities or local government bodies in relation to objects or activities that pose an increased environmental hazard (in accordance with the list approved by the Cabinet of Ministers of Ukraine), in cases provided for by law.

The Law "On Environmental Audit" has opened a new way to ensure environmental safety in Ukraine. Environmental auditing is designed to put a barrier to neglect of environmental requirements in the process of privatization, long-term lease or concession of objects that pose an increased environmental hazard. In certain cases of environmental auditing, accounting for the ecological state of an object, it is transferred or acquired into state or communal ownership, it can play a decisive role in the formation of its price. The application of the new legislation on environmental audit will contribute to the creation and implementation of environmental management systems in various sectors of the Ukrainian economy, will provide greater scientific justification for environmental insurance of activities and objects hazardous to the environment.

Environmental audit is understood as the entrepreneurial activity of environmental auditors or audit organizations to carry out independent nondepartmental qualified analysis and assessment of economic activities, have an impact on the environment, and develop recommendations to reduce the negative impact on the environment and public health. The need to apply environmental audit procedures is determined by the reasons for the insufficient budgetary financing of environmental protection activities, which negatively affected the state of the environment, as well as the possibility of increasing competitiveness in the world market. Environmental audit should be performed in a certain sequence, it provides for three stages: preparation of environmental control at the enterprise; research and information gathering; completion of verification and development of recommendations. The stages are detailed with specific audit engagements and the performance of certain procedures [5].

So, at the first, preparatory, stage, the auditor must determine the goals and objectives of the environmental audit, a list of issues that need to be resolved; conduct a general familiarization with the environmental situation of the enterprise, its technical condition, the availability of the necessary licenses and permits; get acquainted with the environmental policy of the enterprise, carry out a survey of the management on environmental issues; examine internal documentation on the issues under study (orders, protocols, technical documentation, instructions, reports, management information and accounting data). The next step is to conclude an agreement for the implementation of an environmental audit and develop an audit plan and program indicating specific control procedures, deadlines and performers, and location. At the second stage, close contact of the auditor with the staff is established to provide and prepare the necessary information, inspect the territory and premises, observe production processes, conduct the necessary tests, analyzes, examinations, measurements, and the like. Areas of potential environmental risk are identified, the efficiency and economy of the enterprise's system of measures to reduce the environmental risk are assessed. At this stage, an assessment of the enterprise's environmental management system is carried out (a detailed study of the environmental policy, the qualifications of personnel, the formation and use of information on environmental issues, the delineation of personnel duties and responsibilities). At the third stage, the collected information is summarized, the results are summarized, the preliminary results are discussed with the management of the enterprise, the final report and conclusions are drawn up, recommendations are developed and the report is submitted to the audit client. Environmental audit of the agrarian sector is an organizational and economic mechanism of independent (internal and external) control and controlling of production, environmental and environmental activities, regardless of the forms of management [5]. So eco-audit is an organizational and economic mechanism that 
restrains the impact of production on the environment, my elements of planning (programming), motivation, organization and regulation; focused on assessing the compliance of environmental activities with existing environmental legislation, and also on the relationship of environmental activities with the final financial and economic results of production.

Social consequences of the ecological crisis in Ukraine: Life expectancy in Ukraine is on average about 71 years (in Sweden - 80, in Poland - 74). To a large extent, this is due to environmental pollution due to the production activities of enterprises of the mining, metallurgical, chemical industries and the fuel and energy complex. Medical and genetic studies have established that in connection with long-term environmental pollution in the population of the nation, the number of hereditary genetic anomalies is growing. As you know, if this figure reaches $30 \%$, then, according to biological laws, the nation begins to disappear.

When the pollution of the atmosphere is 1.2-1.5 times higher than the sanitary and hygienic standards, diseases of the immune system begin. Today in Ukraine, there are about 1,700 dangerous sources of atmospheric pollution, of which 1,000 are especially dangerous chemical enterprises. The development of agglomeration processes is accompanied by an increase in the technogenic impact on the living environment. In cities, it manifests itself in various forms - changes in the microclimate, pollution of atmospheric air, water and soil, physical (electromagnetic, acoustic, dust) pollution, the formation of a significant amount of not only household, but also industrial waste hazardous to humans.

The Law of Ukraine "On Environmental Audit" provides for two types of environmental audit: voluntary and mandatory.

Voluntary - carried out on the initiative of the management of the audit object or in agreement with it, if the Audit Customer is a third interested party (potential buyer, financial institution, etc.).

Mandatory - carried out by order of interested government agencies for facilities or activities that pose an increased environmental hazard.

Mandatory environmental audit in Ukraine is carried out in the following cases:

- bankruptcy;

- privatization;

- transfer to concession of objects of state and municipal property;

- transfer or acquisition into state or communal ownership;

- transfer to long-term lease of objects of state or municipal property;

- creation of joint ventures on the basis of objects of state and municipal property;

- environmental insurance of objects;

- termination of the production sharing agreement in accordance with the law;

- in other cases provided by law.

It is advisable to carry out an environmental audit when you need:
- determine the compliance of the enterprise with the requirements of environmental legislation;

- check whether environmental payments or penalties of the environmental inspection are not overstated;

- to avoid excessive environmental payments and penalties;

- to reduce the costs of waste management, water supply, electricity, heat, gas supply;

- find out the availability of reserves of raw materials and energy resources at the enterprise;

- to reduce the risk of emergencies related to environmental pollution;

- to increase the investment attractiveness of the enterprise;

- to form the environmental strategy and policy of the enterprise;

- increase the competitiveness of the enterprise and increase customer loyalty through the production of products that meet all environmental, sanitary, and hygienic requirements;

- go international and strengthen the company's position among foreign partners;

- to certify the company's environmental management system for compliance with ISO 14001.

Environmental audit in Ukraine is carried out in order to ensure compliance with the legislation in the field of environmental protection in the course of economic and other activities.

An environmental audit is carried out according to the requirements of state bodies (in cases established by law) or at the initiative of an enterprise, if it is necessary to modernize production and/or technological processes, in order to obtain sound recommendations for rational use of natural resources and environmental protection, and increase efficiency to a level that meets the requirements of legislation.

Eco-controlling is a system of planning, accounting, controlling, analyzing and auditing, which facilitates alternative decision-making in operating and strategic management to achieve enterprises' environmental and economic efficiency [5].

Introduction of eco-controlling as a system of informational support of controlling enterprises' environmental activity will enable: planning, standardizing and calculating environmental expenses, controlling and analyzing data on an enterprise's natural resource use; reporting production data to support making effective, environmentally sustainable managerial decisions; defining aims and measures to reduce loads on the environment; creating conditions to compare operating, investment, financial and environmental activity, their assessment and encouragement; studying and analyzing financial consequences of the environmental activity and determining impacts of these expenses on an enterprise's profitability and product prices; facilitating solution of the problem of defining economic efficiency of environmental measures and assessment of economic losses caused by pollution assessing the importance of healthcare in an enterprise's activity, etc., defining places of emerging expenditures that reflect environmentally 
significant input of raw materials, materials and energy or output of raw material remainders.

In terms of eco-controlling, it is expedient to refer distribution of places of expenditure emergence (control over quality of products and services) [6] to the aims of environment protection only partially, the same referring to other expenditures not involving environment protection (e.g. trucks).

It is evident that in places of emergence of expenditures designated for environmental protection only, all the expenditures can be treated as environmental ones. In other places, environmental expenditures should be specified through corresponding expenditure types. Assessment of environmental impacts by making eco-balances is an important precondition of introducing efficient systems of eco-controlling at industrial enterprises. Assessment of technogenic load on the environment is a new methodological tool for realizing environmental aims and defining ways of their fulfillment. These standards provide for assessing the whole life-cycle of products, in other words, of all the stages starting from mining raw materials to utilization of products or its secondary inclusion into the material cycle. The assessment conducted in the context of ecobalance of products is an efficient tool of producers' and consumers' decision-making [6].

The enterprise's eco-balance can be viewed as a scheme of impacts on the environment (Fig. 1).

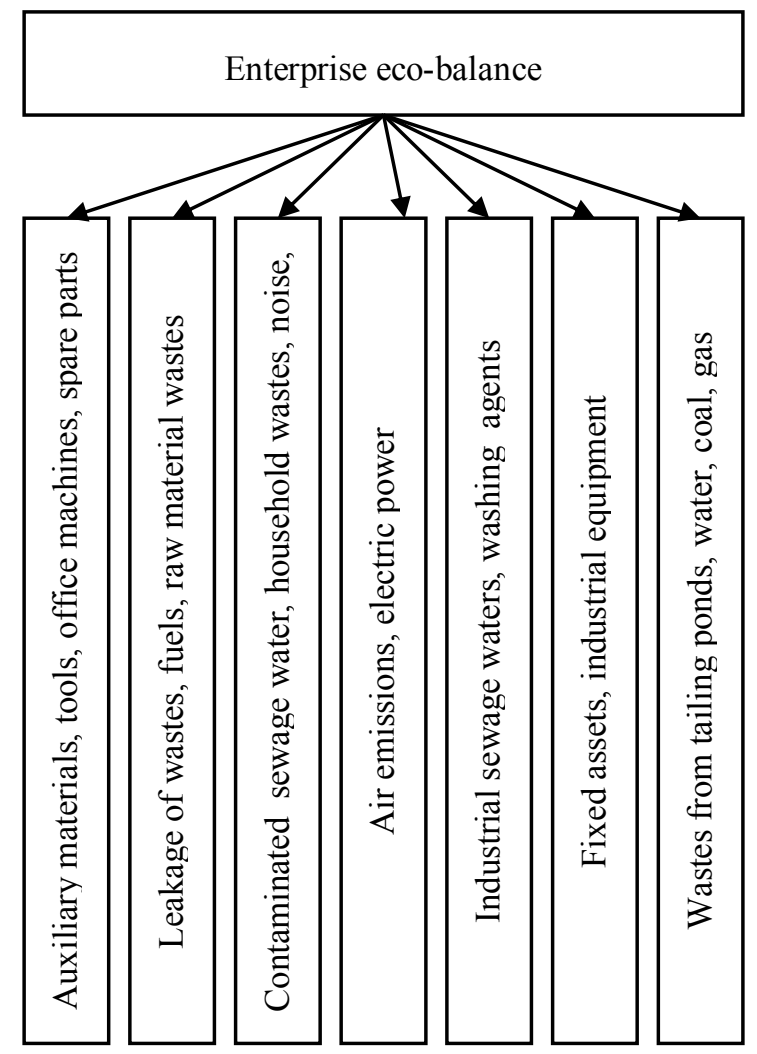

Fig. 1. The scheme of the enterprise's eco-balance.

Eco-balance is aimed at specifying the level of economic and environmental responsibility for its own style and method of economic activity. Eco-balance is grounded on voluntary, systematic, recurrent and objective control over impacts on the environment [7]. Eco-balance is a detailed reflection of environmentally significant resources spent on product manufacturing and resulted wastes as well as their impacts on the environment during a certain time period. Development of eco-balances enables the enterprise to identify environmental aspects and impacts on the environment caused by products during their life-cycle, revealing environmentally narrow spots in the industrial process; informing the community, personnel and consumers about products' impacts on the environment; applying eco-balance data to designing products. To receive a more complete reflection of various aspects of the enterprise's impacts on the environment, there are suggested eco-balances of raw materials, products, production, the enterprise and its location [8].

The enterprise's eco-balance contains information on the input and output of all the materials and energy including material and energy losses as well as the state of real estate, equipment and materials. With that, internal industrial processes are treated as 'a black box' and only flows of raw materials, basic and additional materials, end products and those based on a single production process are considered. Besides, impacts on the environment resulted from production as return air, heat, wastes and sewage waters are taken into account. Eco-controlling is noted for various managerial functions (normative, strategic, operating levels) aimed at integrating operating and strategic aims into concrete plans and actions in such activity areas as development of personnel, design of products, sales, supply, production, quality provision, logistics, distribution, marketing, logistics of products return and re-treatment) [9].

The mechanism of eco-controlling functioning can be presented as a combination of three components analysis, control and regulation of processes aimed at reducing the enterprise's impact on the environment (Fig. 2).

Eco-controlling can be of two types - operating and strategic. In case of operating eco-controlling, the data on development in the limited period are processed and information on events or measures negatively impacting the environment is provided. This type of controlling is aimed at improving the environment in the short-term period. In the strategic eco-controlling, actual indices are compared with the scheduled ones and the potential of improving the results and risks of increasing expenses or deterioration of activity results is determined due to timely data on development trends [10]. Controlling is treated as a modern technology and the system of intellectualizing business processes, which, being managers' philosophy and a controlling tool of management systems, involves all the managerial, executive and supplying business-processes within a certain enterprise.

This enables forming a specific technology of total process controlling, which, unlike the current ones, enables including all the business-processes of the given enterprise [11]. 




Fig. 2. The mechanism of eco-controlling functioning.

Industrial wastes are environmental pollutants. In Ukraine, the main source of waste generation is mining, chemical and metallurgical, machine building, fuel and energy, complexes.

Waste containing heavy metals, oil products, pesticides (pesticides) unsuitable for use, the bulk of which is generated in Donetsk and Dnipropetrovs'k regions.

There are almost 20,000 hectares of land under the toxic waste storage facilities. According to statistics, approximately $80 \%$ of all harmful emissions into the air are the result of energy processes (extraction, processing and use of energy resources).

Environmentalists analyzed the published nonfinancial reporting for the period 2015-2019. For the study, enterprises were selected, in particular, OJSC "EVRAZ Dneprovsky Metallurgical Plant", Dnepr, "Arcelor Mittal Kryvyi Rih". When analyzing the nonfinancial reporting of selected enterprises, it was found that there is a total advantage of using a passive communication strategy with the relative weakness of external stakeholders.

Non-financial reporting is a relatively new corporate practice in Ukraine; therefore, a unified approach to the definition of this concept has not yet been developed. In 2017-2019 At PJSC "Arcelor Mittal Kryvyi Rih" there is an increase in production volumes by $15.12 \%$ and $9 \%$, respectively.

During this period, there has been a significant increase in the volume of discharges into the atmosphere and water resources by $6 \%$ and $8 \%$, respectively. The enterprise is modernizing sinter plant-2 (implementation period - 2015-2021), major overhaul of the 1 st category with reconstruction of blast furnace - 9 (implementation period - 2016-2021), which will significantly reduce the use of expensive natural gas and coke used in smelting pig iron, improve energy efficiency and improve the environmental situation in the region.

The process of recycling waste in its own production needs to be optimized, which will increase the cost efficiency of waste management.

The increase in expenses for the protection of atmospheric air is also associated with the introduction of an integrated air monitoring system in the area of production impact.

To optimize environmental losses, enterprises are recommended to introduce: accelerated depreciation of fixed assets of environmental importance (treatment facilities, environmental quality monitoring systems); material and non-material incentives for personnel in the development of engineering solutions and rationalization proposals for the greening of production activities and the system of environmental management, energy efficiency and optimization of waste management; adherence to ISO and EMAS standards in the field of environmental protection, control over the effectiveness of the environmental responsibility system at enterprises.

It should be emphasized that in addition to optimizing the environmental strategy of the enterprise, these measures will create a positive image of the company, increase the competitiveness of products due to "green" advantages, which is especially important in European sales markets. At PJSC "Arcelor Mittal Kryvyi Rih", the indicator of the ecological loss rate of products is satisfactory, although its growth on average by $0.004 \%$ per year is mainly due to inflationary processes, which are reflected in the growth of income from sales of manufactured products.

An increase in the share of recovered environmental costs is observed at the enterprise, which negatively affects the financial results of the enterprise, because the unrecovered environmental costs are compensated from profit, which requires strengthening control in the field of tax planning and environmental monitoring. Because of strengthening control in this area, during 2016-2018. The enterprise did not pay fines or penalties on profit. The enterprise is characterized by an increase in the volume of environmental costs, on average, the increase occurs by $26 \%$ per year.

Regarding PJSC "EVRAZ DMZ", it is worth noting that today the enterprise is the only metallurgical plant in Ukraine, where, without the injection of pulverized coal, natural gas was removed using blast furnace technology. This made it possible to significantly reduce the energy consumption of production without significant impact on its volumes. During the study period (2015-2019), the enterprise has seen a steady increase in the production of marketable products. This trend also entails an increase in emissions into the environment.

The average growth rate of production volumes for the year was $5.18 \%$, which in absolute terms as of 2018 
amounted to $19,670,000$ tons. The volume of annual emissions into the atmosphere on average for the year increased by $4.84 \%$, the absolute value of $1 \%$ of the increase was 9,400,000 tons (as of 2018). The trend towards a decrease in the total annual volume of discharges into water bodies is positive. On average, discharges decreased by $6.57 \%$ over the year.

The enterprise is a water user of the Dnepr River and remains one of the main pollutants, which requires additional environmental protection measures. In the field of waste management, there is an annual increase in waste generation by an average of $1.43 \%$, which is a natural trend with an increase in production volumes. The annual volume of used waste is increasing by an average of $7.2 \%$ per year.

This effect was achieved by increasing the use of waste in our own production.

Despite the increase in production volumes, on average, the coefficient of waste intensity in the category "air emissions" remains at a constant level. This is undoubtedly a positive trend, indicating the high efficiency of the measures introduced at the enterprise to protect the atmospheric air.

Thus, the coefficient of waste intensity in the category of "discharges into water bodies" in 2017 compared to 2015 increased by $4.86 \%$, and on average, the annual growth was $1.09 \%$. In the category of waste use, it should be noted that the coefficient increased annually by an average of $5.1 \%$, which is due to the use of waste for construction projects of the enterprise.

Enterprises are participants in regional and local environmental programs, such as "Long-term program to solve environmental problems of Kryvbas and improve the state of the environment for 2011-2022", "Dnipropetrovs'k regional comprehensive program (strategy) of environmental safety and prevention of climate change for 2016-2025 years".

A high level of atmospheric air pollution is characteristic of the specifics of the activities of metallurgical enterprises in old industrial regions, which characterize the Dnipropetrovs'k region; the studied enterprises have certificates of the environmental management system and regularly undergo appropriate audits. Nevertheless, it should be emphasized the low level of assessments of the effectiveness of environmental management at "EVRAZ DMZ". Particular attention should be paid to issues of improving the effectiveness of measures in such an assessment category as the preparation and publication of nonfinancial reporting.

At the same time, the non-financial reporting of Arcelor Mittal Kryvyi Rih is prepared in accordance with the GRI system and is annually celebrated at the All-Ukrainian competitions for corporate social responsibility. As a result of the analysis of the assessment of the levels of significance of the proposed categories, the following conclusions can be drawn.

The experts identified the following as the most significant assessment categories that have the greatest impact on the level of the enterprise's environmental initiative: activities to compensate for general environmental damage, protection of atmospheric air and water bodies, the users of which are enterprises, the effectiveness of environmental management and environmental audit.

Among the recommendations for optimizing environmental protection costs, it is worth highlighting the following aspects: improving the non-financial reporting system, strengthening control in this area; conducting additional internal environmental audits to establish compliance with international environmental standards, carrying out a comprehensive assessment of the level of environmental responsibility of the enterprise with the subsequent development of recommendations to improve its efficiency.

The amount of compensation for losses for the excess emission of one ton of a pollutant into the air is calculated on the basis of the size of the minimum wage established on the date of detection of the violation, multiplied by a factor of 1.1 , taking into account the regulatory factors and the relative hazard indicator of each pollutant substances. The amount of losses is calculated using the formula (1) [12]:

$$
C==m_{i} \cdot 1,1 \ddot{I} \cdot A_{i} \cdot K_{t} \cdot K_{c^{3}}
$$

where 3 - amount of losses, UAH;

$m_{i}$ - the mass of the excess emission of the $i$-th pollutant, $\mathrm{t}$;

$1.1 \Pi$ - the size of the minimum wage $(\mathrm{P})$ as of the date of detection of the violation for one ton of the conditional pollutant multiplied by the coefficient (1.1), $\mathrm{UAH} / \mathrm{t}$;

$A_{i}$ - dimensionless indicator of the relative hazard of the $i$-th pollutant;

$K_{i}$ - coefficient taking into account the territorial socioecological characteristics;

$K_{3 \mathrm{i}}-$ a coefficient depending on the level of atmospheric air pollution in the settlement with the $i$-th pollutant.

The total amount of compensation for damages is calculated as the sum of the amount of losses for the excess emission of each pollutant into the atmospheric air.

\section{Conclusions}

Under current economic conditions, the eco-controlling system is of particular importance as it is aimed at controlling current analysis of scheduled and actual indices in order to exclude errors and deviations of both the present-day and the future.

At the initial stage of its implementation, ecocontrolling reveals itself as a system of informing of negative deviations in the enterprise's activity for taking timely preventive measures.

In the enterprise's activity, eco-controlling is an integral concept of enterprise management aimed at revealing chances and risks of receiving revenues.

In the latest years, enterprise managers have to face the problem of searching for and applying management methods, which are efficient and useful. 
Within the system of anti-crisis management, ecocontrolling ensures implementation of the enterprise's strategic potential and achievement of aims of liquidity and profitability. In our opinion, in the nearest future, eco-controlling should become a priority in the enterprise's management system.

The role of environmental audit in the environmental monitoring system is as follows:

- environmental audit is an element of these systems and the requirements for the presence of such an element are set by the DSTU ISO 14001 standard. So, environmental audit should be considered as an integral part of environmental management systems.

- environmental audit is a tool for the formation of the environmental policy of the object or territory subject to audit.

Of course, the scope and role of environmental audit is very wide and multifaceted. An environmental audit is considered as:

1) organizational and managerial tool for ensuring the environmental safety of the facility;

2 ) as an instrument of state ensuring the environmental safety of objects and territories (if it is considered on a national scale, when the "state system of environmental audit" has been introduced and operates;

3 ) as a tool to ensure the prevention and limitation of the consequences of accidents at the inspected facility (if we are talking about an environmental audit in order to determine environmental risks);

4) as an element of the environmental insurance system (if we are talking about an insurance environmental audit in order to determine the likelihood of emergencies and possible consequences. In this case, the audit results will affect the "economy" of the environmental insurance process, that is, the amount of insured amounts and tariffs);

5 ) as a new direction of activity in the market of environmental services (we are talking about the fact that a new direction for entrepreneurship appears on the market of environmental services, which is also very important in the context of state priorities for the development of small and medium-sized businesses).

We are quite optimistic about the prospects for introducing international standards in Ukraine. Measures taken at the state level in combination with market trends, raising the level of consciousness and business culture of managers will lead to the fact that Ukrainian enterprises will widely apply the principles of environmental controlling and auditing, which are a very important component that ensures the sustainable development of not only enterprises, but also ultimately the whole society.

Eco-audit should become an effective means of regulating the relationship between production and the environment. Based on the results of the audit, plans for agricultural and environmental activities are developed for both individual agricultural enterprises and for regions, the amount of subsidies, the legality of price increases and their value, as well as sanctions for offenders are determined.

\section{References}

1. I.S. Marekha, Resource saving as a form of rationalization of nature use in the conditions of modern economic relations, Global and national problems of economy, 2 (2014) http://www.globalnational.in.ua/archive/2-2014/187.pdf

2. Some facts about garbage http://climbinduk.org/node/256

3. K. Walsh, Key financial indicators. Analysis and management of enterprise development (2001)

4. T. Lembert, Key problems of the head. 50 proven ways to solve problems: a guide (2001)

5. T.A. Kirsanova, Environmental controlling is an environmental management tool (2004)

6. N.V. Pakhomova, Environmental management (2003)

7. U. Stoltenberg BetrieblichesOekocontrolling: Leitfadenfuerdie Praxis (1996)

8. H. Matukova, (ed), Innovative Forms of Management for Companies Under Rehabilitation Advances in Economics, Business and Management Research III International Scientific Congress Society of Ambient Intelligence 2020 (ISC-SAI 2020) Advances in Economics, Business and Management Research 129 (2020) DOI: https://dx.doi.org/10.2991/aebmr.k.200318.01 3

9. L.I. Maximov, Organizational and methodological aspects of operational eco-controlling (2005)

10. I.A. Markina, Controlling for managers: textbook. way (2013)

11. E. Shvydky, Controlling as a technology of intellectualization of business process management in enterprises: (financial-accounting-analytical aspects) (2012)

12. Order of the Ministry of energy and environmental protection of Ukraine No. 277 (2020) April, 28 "On approval of the Methodology for calculating the amount of compensation for losses caused to the state as a result of excess emissions of pollutants into the atmospheric air" http://search.ligazakon.ua/l doc2.nsf/link1/RE34697.html 